\title{
FERRAMENTAS DO ENDOMARKETING PARA AVALIAR E PROPOR MELHORIAS NO CLIMA ORGANIZACIONAL DE UMA BIBLIOTECA UNIVERSITÁRIA PÚBLICA ${ }^{1}$
}

\author{
ENDOMARKETING TOOLS TO EVALUATE AND SUGGEST EFFORTS TO THE \\ ORGANIZATIONAL CLIMAT OF A PUBLIC UNIVERSITY LIBRARY
}

\author{
Teresa Cristina Oliveira Peres ${ }^{2}$
}

\section{RESUMO}

O trabalho tem por objetivo propor melhorias em uma biblioteca universitária pública a partir de uma pesquisa de clima organizacional. Realizada com o intuito de identificar os seus pontos fracos, expectativas e aspirações da equipe, busca um entendimento das relações internas e um levantamento das necessidades. A interferência direta do ser humano nas atividades que interagem com o cliente final aumenta os investimentos das empresas em planos e estruturas que visam abordá-lo e motivá-lo, de acordo com os objetivos a que se propõe a organização. Os resultados obtidos na pesquisa contribuíram para a criação de um Programa de Endomarketing que poderá direcionar a administração da biblioteca na busca de melhorias das relações ambientais, assim como das relações clientes internos x clientes externos.

\section{PALAVRAS-CHAVE}

Clima organizacional.Endomarketing.Bibliotecas (recursos humanos).

\begin{abstract}
This paper aims to propose improvements in a public university library from an organizational climate survey, carried out in order to identify its weaknesses, expectations and aspirations, seeking an understanding of the internal relations and a survey of the needs. The direct interference of human activities that involve interaction with the customer increase business investments through plans and structures that aim to approach and motivate him, according to the goals that sets the organization. The results obtained in the research contributed to the creation of an Internal Endomarketing Program that can direct the administration of the library in search of improvements of environmental relations as well as the relations of internal customers vs. external customers.
\end{abstract}

\section{KEYWORDS}

Organizational climate. Endomarketing. Libraries (human resources).

1Trabalho originado do TCC desenvolvido pela autora para o Programa de Especialização em Administração de Serviços da Fundação Vanzolini da Universidade de São Paulo.

${ }^{2}$ Bibliotecária Especialista em Administração de Serviços, Técnica de Documentação e Informação da Biblioteca Dante Moreira Leite do Instituto de Psicologia da USP, São Paulo, SP. E-mail: tercrist@usp.br. 


\section{INTRODUÇÃO}

O "Endomarketing" tornou-se uma ferramenta de extrema importância para as organizações, focando a sintonia e a sincronização de todos os colaboradores da empresa, tornando o colaborador um aliado e fomentando a idéia de que seu sucesso está ligado ao sucesso da organização.

Para a criação de um Programa de Endomarketing na empresa, o estudo de clima organizacional é fundamental para se conhecer a satisfação dos seus colaboradores em relação à organização.

Nesse contexto, o objetivo desse trabalho é verificar e analisar o clima organizacional dentro de uma biblioteca universitária pública, identificando o grau de satisfação de seus colaboradores.

\section{REVISÃO DE LITERATURA}

\section{Endomarketing}

Segundo Dias (2007), a idéia de se criar um ambiente participativo e motivador nas empresas surgiu por volta de 1923. Em 1927, Mayo pesquisou a relação entre iluminação e produtividade, experiência que durou até 1932, e mostrou a influência de fatores psicológicos no trabalho (ESCOLA das relações humanas, s.d.).

No Brasil, Bekin (1995) é considerado o pioneiro no uso do termo "Endomarketing" e o utilizou pela primeira vez em 1975. De acordo com o autor, "Endomarketing consiste em ações de marketing voltadas para o público interno da empresa, com o fim de promover entre seus colaboradores e departamentos valores destinados a servir o cliente" (p. 2).

Dias (2007), diz que o "Endomarketing" hoje pode ser entendido como um processo estruturado, alinhado ao planejamento estratégico empresarial, visando melhorias da comunicação e buscando a relação com ganhos de produtividade nas organizações. 
Para Bekin, citado por Rodrigues (2003), Endomarketing consiste em realizar ações de Marketing voltadas para o público interno da empresa, com o objetivo de atrair e reter esses colaboradores. "Uma vez satisfeitos com a empresa, eles acabam produzindo mais e melhor e, como conseqüência, a empresa consegue obter resultados muito mais eficientes, entre os quais, maior fidelização de seus clientes externos".

Castro (2002) define "Endomarketing" como a utilização de técnicas e instrumentos próprios do Marketing em relação ao público interno da organização, com foco final na melhoria do valor oferecido e do atendimento prestado aos clientes externos.

De acordo com Dias (2007, p. 22), uma forma de integração muito utilizada hoje nas organizações é a intranet.

O advento da tecnologia da informação trouxe mais facilidade no envio e recepção de mensagens aos gerentes e operadores. O gerente recebe a mensagem via correio eletrônico e repassa aos operadores a informação oficial, livre de boatos. Para os empregados, a informação chega de forma mais fácil e rápida, facilitando a tomada de decisões e o despertar da criatividade para criação de melhorias operacionais.

Moreira (s.d.) em seu artigo "Ferramentas de Endomarketing" fala da importância do Endomarketing, enquanto instrumento de sedimentação e aponta alguns recursos do Endomarketing, como:

- Jornal Interno: útil para uniformizar a linguagem, promover encontros, difundir idéias, revelar talentos e motivar as pessoas;

- Videojornal: segue o mesmo princípio do jornal interno, porém utiliza o recurso do vídeo;

- Feira de Negócios: os próprios colaboradores da empresa têm que montar uma feira (com stands, atrativos etc.). O objetivo da Feira de Negócios é fazer com que cada área da empresa apresente os seus serviços/produtos para as outras áreas. 
Idéias simples podem gerar resultados no ambiente de trabalho como a integração entre os colaboradores. Pequenas premiações, palavras de incentivo, interesse nas atividades e reconhecimento podem ajudar os colaboradores a trabalhar com mais motivação.

Nesse contexto, a alta administração passa a conhecer, através dessas ações, os reais interesses de seus empregados, podendo assim criar um clima harmonioso e de envolvimento com o trabalho.

\section{Comunicação Interna}

A comunicação interna, segundo Kotler (1998), deve contribuir para o exercício da cidadania e para a valorização do homem. A oportunidade de se manifestar e de se comunicar livremente canalizará energias para fins construtivos, tanto do ponto de vista pessoal quanto profissional. Se considerarmos que a pessoa passa a maior parte do seu dia dentro da organização, as razões são muitas para que o ambiente de trabalho seja o mais agradável possível.

Sendo assim, um serviço de comunicação agiliza o processo comunicativo e promove a integração entre os diferentes setores. Os investimentos a serem feitos só trarão benefícios para a organização, considerando que o público interno é um agente multiplicador e acaba tornando-se um porta-voz da organização positiva ou negativamente perante seus familiares e contatos sociais.

“A comunicação interna permitirá que ele [funcionário] seja bem informado e que a organização antecipe respostas para suas expectativas. Isso ajudará a administrar conflitos e a buscar soluções preventivas" (KOTLER, 1998, p. 129). 


\section{MATERIAIS E MÉTODOS}

\section{Instituição}

A instituição escolhida neste estudo é uma biblioteca universitária pública que atende a uma clientela seleta e exigente e sempre primou pela excelência no atendimento e na prestação de serviços aos seus clientes.

De acordo com informações presentes no site da instituição estudada (BIBLIOTECA, s.d.), a organização é composta por cinco estruturas funcionais: 1) Diretoria; 2) Biblioteca Virtual em Saúde - Psicologia (BVS-Psi, www.bvs-psi.org.br); 3) Seção de Aquisição e Processamento da Informação; 4) Seção de Informação e Divulgação; 5) Seção de Multimeios, Memória e Apoio às Publicações.

A Biblioteca tem como política básica:

- Missão: coordenar ações para seleção, reunião, organização e disseminação da informação em Psicologia no Brasil e na América Latina, enquanto apoio ao ensino, pesquisa, extensão e práticas profissionais, contribuindo para a geração, preservação e visibilidade do conhecimento na área.

- Valores: democratizar o acesso aos recursos informacionais com excelência e compromisso, visando o crescimento e a construção da democracia, assim como a tolerância, equiidade e liberdade, contribuindo para a promoção de uma Psicologia plural, comprometida com a responsabilidade social.

- Visão: ser um centro ativo na gestão da informação psicológica na América Latina. 
Para a sociedade, a Biblioteca em questão tem como política a "criação e manutenção de fontes e serviços de acesso aberto para disponibilização de informação e do documento ao maior número de pessoas possível” (BIBLIOTECA, s.d.).

\section{Instrumento e Procedimentos de Coleta}

A pesquisa foi realizada por meio de um questionário, aplicado aos colaboradores da organização estudada.

Considerando o perfil da instituição, para a elaboração do questionário, selecionou-se 10 variáveis de 34 apontadas no estudo de Luz (2003):

1) gestão: revela a satisfação dos colaboradores com os seus gestores, qualidade da supervisão, capacidade técnica, humana e administrativa;

2) salários/benefícios: uma das principais variáveis a ser pesquisada dentro de uma empresa; os salários estão sempre na mesa de discussão;

3) valorização dos colaboradores: verifica se os colaboradores estão satisfeitos com a valorização oferecida pela empresa;

4) comunicação: essencial para uma organização que lida com atendimento ao público e oferece serviços de primeira linha ao mercado;

5) integração entre os departamentos da empresa: possibilita que todos os colaboradores estejam em sintonia com os objetivos da empresa;

6) treinamento/desenvolvimento/carreira/progresso e realização: sendo uma empresa em crescimento é necessário avaliar sua postura em relação às oportunidades de crescimento conjunto que oferece aos seus colaboradores;

7) relacionamento interpessoal: essencial para qualquer área do mercado; 
8) condições físicas de trabalho: condições de conforto, instalações em geral, riscos de acidentes no trabalho etc.;

9) participação: a participação de todos os colaboradores propicia um alto grau de conhecimentos, tanto dos produtos como dos processos;

10) imagem da empresa: opinião dos colaboradores sobre a visão da empresa no mercado.

Os questionários foram distribuídos aos 25 colaboradores da organização nos dias 30 e 31 de julho de 2008. Solicitou-se aos participantes que os mesmos fossem preenchidos e colocados em uma caixa na copa da Biblioteca. Pediu-se, também, que o questionário fosse respondido na própria empresa, evitando-se assim "o risco de influências de terceiros e também o risco de perdas ou a não devolução em tempo hábil” (LUZ, 2003, p. 58).

O questionário foi composto por 50 questões fechadas e uma aberta que tiveram como base as 10 variáveis selecionadas do trabalho de Luz (2003).

Para segurança, foi garantido aos colaboradores o anonimato para que os mesmos pudessem ter maior liberdade nas respostas, evitando-se assim omissão ou respostas incoerentes.

\section{Análise dos Dados}

Dos 25 questionários distribuídos, retornaram 18, perfazendo um total de $72 \%$ de retorno.

Para saber qual o percentual de satisfação, foi feita uma entrevista com a Diretora da Biblioteca, que nos relatou: "Para nós um percentual considerável será de $80 \%$ de satisfação, pois essa Biblioteca é uma instituição que tem seus objetivos voltados para o desenvolvimento de produtos e serviços qualitativos e especializados. É necessário ter clientes internos satisfeitos e com um alto grau de envolvimento".

Para realizar a análise dos dados, utilizou-se o programa Excel. A tabulação foi realizada por pergunta e por variável. 
Destacamos, dentro das variáveis, os pontos fracos da empresa e estabelecemos a necessidade de ações para melhoria levando em conta as perguntas que não atingiram o limite estabelecido de $80 \%$ de respostas positivas.

Algumas perguntas, portanto, mesmo tendo a maioria dos colaboradores satisfeitos, foram incluídas nos pontos fracos a serem melhorados, para atenderem as expectativas da organização, que considera aceitável o percentual de $80 \%$ de satisfação.

Nesse contexto, analisamos as perguntas dentro de cada variável e verificamos quais dentre elas tinham um percentual muito abaixo do esperado pela Diretora da Biblioteca.

É importante ressaltar que o limite estabelecido pela organização, 80\%, é considerado alto frente ao comumente estabelecido pelas organizações: $65-70 \%$. Esse alto grau de expectativa fez com que muitas variáveis fossem consideradas com satisfação insuficiente.

\section{PROPOSTA DE PLANO DE AÇÕES}

A partir dos resultados obtidos, levantou-se os pontos fracos e formulou-se um plano de ações de melhoria para cada uma das 10 variáveis.

Essas ações são apresentadas na tabela 1.

\section{TABELA 1}

Análise por pergunta

\begin{tabular}{|c|c|c|}
\hline Variáveis & Pontos fracos & Ações \\
\hline 1) Gestão & $\begin{array}{llr}\text { Falta de incentivo por parte } \\
\text { do supervisor para o } \\
\text { desenvolvimento } & \text { de um } \\
\text { trabalho bem feito. } & & \\
\end{array}$ & $\begin{array}{l}\text { - Capacitação de líderes, visando } \\
\text { melhor entendimento entre liderança e } \\
\text { colaboradores. }\end{array}$ \\
\hline $\begin{array}{l}\text { 2) } \\
\text { Salário/benefíc } \\
\mathrm{s}\end{array}$ & $\begin{array}{l}\text { Políticas de salários e } \\
\text { benefícios: mal entendidos ou } \\
\text { falta de clareza para os } \\
\text { colaboradores. }\end{array}$ & $\begin{array}{l}\text { - Realização de Workshop no qual os } \\
\text { benefícios sejam claramente } \\
\text { explicados; } \\
\text { - readequação de cargos e salários; } \\
\text { - desenvolvimento de políticas claras } \\
\text { para o crescimento profissional das } \\
\text { pessoas. }\end{array}$ \\
\hline 3) Valorização/ & $\begin{array}{l}\text { Crescimento } \\
\text { reconhecimento }\end{array}$ & $\begin{array}{l}\text { - Desenvolvimento de um plano de } \\
\text { carreira aberto a mudanças e }\end{array}$ \\
\hline
\end{tabular}

(C) Rev. Dig. Bibl. Ci. Inf., Campinas, v.9, n.2, p.12-24, jan./jun. 2012 - ISSN 1678-765X

http://www.sbu.unicamp.br/seer/ojs/index.php/sbu_rci/index 


\begin{tabular}{|c|c|c|}
\hline reconhecimento & competência. & $\begin{array}{l}\text { atualizações; } \\
\text { - painéis com o nome do funcionário } \\
\text { e o trabalho desenvolvido como forma } \\
\text { de reconhecimento. }\end{array}$ \\
\hline 4) Comunicação & $\begin{array}{l}\text { Deficiência nos meios de } \\
\text { comunicação interna. }\end{array}$ & $\begin{array}{l}\text { - Uso de jornais internos, convenções } \\
\text { e intranet para estreitar as relações } \\
\text { com os colaboradores; } \\
\text { - estimular o diálogo e a troca de } \\
\text { informações entre todos os níveis da } \\
\text { pirâmide organi-zacional, na busca da } \\
\text { qualidade das relações humanas. }\end{array}$ \\
\hline $\begin{array}{l}\text { 5) Integração } \\
\text { entre } \quad \text { os } \\
\text { departamentos }\end{array}$ & $\begin{array}{l}\text { Falta de cooperação e apoio } \\
\text { na equipe. }\end{array}$ & $\begin{array}{l}\text { - Palestra de envolvimento de } \\
\text { equipes; } \\
\text { - dinâmicas de grupo; } \\
\text { - reuniões informais. }\end{array}$ \\
\hline $\begin{array}{l}\text { 6) Treinamento/ } \\
\text { desenvolvimento/ } \\
\text { carreira/progress } \\
\text { o/ } \\
\text { realização }\end{array}$ & $\begin{array}{l}\text { Programa de incentivo à } \\
\text { educação } \\
\text { continuada. } \\
\text { Aproveitamento de pessoal. } \\
\text { Programa de integração para } \\
\text { novos colaboradores. }\end{array}$ & $\begin{array}{l}\text { - Projeto de voluntariado, } \\
\text { incentivando a participação dos } \\
\text { colaboradores; } \\
\text { - escolha de um funcionário } \\
\text { comunicativo para acompanhar os } \\
\text { novos colaboradores durante a } \\
\text { integração de departamentos; } \\
\text { - melhor aproveitamento dos } \\
\text { conhecimentos dos colaboradores; } \\
\text { - indicação de colaboradores para } \\
\text { fazer capacitação. }\end{array}$ \\
\hline
\end{tabular}

7) Confiança nas decisões

Relacionamento interpessoal $\begin{array}{llr}\text { Confiança } & \text { nas decisões } \\ \text { tomadas } & \text { pelo supervisor }\end{array}$ imediato. Discriminação por cargo.
- Projeto envolvendo todos os colaboradores, com a realização de diferentes eventos de integração, nos quais a interação entre todos seja o foco principal;

- capacitação de liderança para melhorar o relacionamento com seus subordinados.

\begin{tabular}{llllll}
\hline & & \multicolumn{2}{l}{ Equipamentos de segurança } & Campanha, através de folders e \\
8) Condições & para paração dos & cartazes em pontos estratégicos, \\
físicas & de & colaboradores. Equipamentos & visando a conscientização dos \\
trabalho & & para desenvolvimento do & colaboradores sobre o que existe de \\
& & trabalho. & Condições & material para protegê-los e a \\
& ambientais do trabalho. & importância de seu uso.. & \\
\hline
\end{tabular}

(c) Rev. Dig. Bibl. Ci. Inf., Campinas, v.9, n.2, p.12-24, jan./jun. 2012 - ISSN 1678-765X http://www.sbu.unicamp.br/seer/ojs/index.php/sbu_rci/index 
Novas decisões tomadas pela

9) Participação empresa.

Abertura para novas idéias nos setores.
ARTIGO

- Incentivo de projetos em grupo entre os setores com a aplicação de brainstorming;

- Informativos, através da intranet, sobre novas decisões e programas em desenvolvimento pela empresa;

- O funcionário poderá interagir contribuindo com sugestões.

Imagem da empresa entre os colaboradores.

Trabalhos envolvendo a comunidade.

Orgulho do desempenho.
- Projeto em que os colaboradores contribuam com assuntos de seu interesse em palestras e cursos para a comunidade;

- Desenvolvimento de uma campanha para modernizar a imagem da Biblioteca entre os colaboradores com o auxílio de um especialista em Relações Públicas.

De acordo com Mello (2007), equipes que desenvolvem ações de melhorias devem trabalhar com a estrutura, com os processos e com as pessoas da organização.

Nesse contexto, sugere-se que as ações de melhoria de clima organizacional apresentadas na tabela 1 sejam desenvolvidas na instituição estudada por gerentes e colaboradores.

\section{CONSIDERAÇÕES FINAIS}

A avaliação do clima organizacional é um importante instrumento de levantamento de opiniões e percepções para conhecer e entender melhor o comportamento dos colaboradores dentro das organizações.

Por meio da avaliação do clima organizacional, aferimos o grau de satisfação ou insatisfação dos colaboradores, fornecendo bases para a definição de estratégias que potencializem os fatores de satisfação e minimizem as causas de insatisfação no trabalho.

$\mathrm{Na}$ literatura, encontramos vários modelos para pesquisa do clima organizacional, porém não existe um modelo universal que possa ser aplicado em todos os tipos de organizações. 
O estudo do clima organizacional nos permitiu entender a importância de um ambiente de trabalho satisfatório para o funcionário, no que diz respeito à sua satisfação com relação à organização, colegas de trabalho, salário e benefícios, uma vez que esses fatores influenciam diretamente sobre o objetivo final da organização, tendo em vista o cliente externo.

A identificação da realidade do ambiente interno existente na organização analisada e a sugestão de ações pelo grupo contribuíram para que a organização definisse os pontos vitais que devem ser trabalhados na administração para melhoria do desempenho geral, objetivando a excelência de suas atividades.

Com o intuito de melhorar a situação interna, a organização estudada se dispôs a utilizar esta pesquisa para entender e colocar em prática, através do Endomarketing, as melhorias aqui sugeridas.

Nesse contexto, a presente pesquisa proporcionou o conhecimento mais aprofundado do quadro de colaboradores da Biblioteca. Com a aplicação das ações de melhoria sugeridas no estudo, a instituição poderá proporcionar um ambiente motivador e de grande envolvimento, comunicando adequadamente seus objetivos para obter o comprometimento de todos os colaboradores no atendimento das expectativas de seus clientes, os usuários da Biblioteca. 


\section{REFERÊNCIAS}

BEKIN, S. F. Conversando sobre endomarketing. São Paulo: Makron Books, 1995.

BIBLIOTECA. Apresentação: Biblioteca Dante Moreira Leite. São Paulo, s.d. Disponível em: $<$ http://www.ip.usp.br/portal/index.php?option=com_content $\&$ view=article\&id=1233\&Itemid=1 28>. Acesso em: 21 jun. 2008.

CASTRO, C. F. M. F. Endomarketing e orientação para o cliente externo. Administração em Revista, Brasília, v. 2, n. 1, p. 13-24, jan./jun. 2002.

DIAS, J. G. G. Endomarketing: um instrumento estratégico na busca da melhoria da competitividade empresarial. São Paulo: Livro Pronto, 2007.

ESCOLA das relações humanas. Principais vultos. S.d. Disponível em:

http://www.professorcezar.adm.br/Textos/Teoria\%20das\%20relacoes\%20humanas.pdf $>$. Acesso em: 26 ago. 2009.

KOTLER, P. Administração de marketing - Análise, planejamento, implementação e controle. 5. ed. São Paulo: Atlas, 1998.

LUZ, R. Gestão de clima organizacional. Rio de Janeiro: Qualitymark, 2003.

MELLO, Á. L. Como transformar os resultados de uma pesquisa de clima organizacional em um plano de ação. 2007. Disponível em: <http://www.slideshare.net/alvaromello/apresentaomp1/>. Acesso em: 26 ago. 2008.

MOREIRA, J. C. T. Ferramentas de endomarketing: jornal, video e até uma feira interna. S.d. Disponível em: 〈http://www.mindconsultoria.com.br/artigos.asp?cod=12 > . Acesso em: 21 jun. 2008.

RODRIGUES, C. Lançando mão de técnicas de marketing, as empresas conquistam um cliente especial: seus colaboradores. Revista Canal RH, v. 3, n. 27, out. 2003. Disponível em: <http://www.endomarketing.com.br/artigo2.htm>. Acesso em: 13 jun. 2008. 
Recebido em:07/01/2011

Publicado em:10/01/2012 